\title{
Sigmoid Colon Volvulus: Surgical Management at Kati BSS Hospital (Mali)
}

\author{
Koniba Keita1 ${ }^{*}$, Abdoulaye Diarra1, Salia Coulibaly², Sidiki Keita1, Issa Traore1, \\ Moussa Doumbia' ${ }^{1}$, Fadima Tall ${ }^{3}$, Daouda Diallo³, Oulematou Coulibaly ${ }^{3}$, Assitan Kone', \\ Boubacar Kone1, Daouda Konate ${ }^{4}$, Amadou Kassongue ${ }^{5}$, Moussa Salifou Diallo5, \\ Ismael Konare ${ }^{1}$, Drissa Traore ${ }^{1}$, Nouhoum Ongoiba ${ }^{1}$
}

${ }^{1}$ General Surgery Department, Kati, Mali

${ }^{2}$ Medical Imaging Department, Kati, Mali

${ }^{3}$ Anesthesia Resuscitation Department, Kati, Mali

${ }^{4}$ Ophthalmology Department of Kati, Kati, Mali

${ }^{5}$ Department of Urology of Kati, Kati, Mali

Email: ^koniskeita73@gmail.com

How to cite this paper: Keita, K., Diarra, A., Coulibaly, S., Keita, S., Traore, I., Doumbia, M., Tall, F., Diallo, D., Coulibaly, O., Kone, A., Kone, B., Konate, D., Kassongue, A., Diallo, M.S., Konare, I., Traore, D. and Ongoiba, N. (2019) Sigmoid Colon Volvulus: Surgical Management at Kati BSS Hospital (Mali). Surgical Science, 10, 76-82. https://doi.org/10.4236/ss.2019.103010

Received: February 19, 2019

Accepted: March 15, 2019

Published: March 18, 2019

Copyright () 2019 by author(s) and Scientific Research Publishing Inc. This work is licensed under the Creative Commons Attribution-NonCommercial International License (CC BY-NC 4.0). http://creativecommons.org/licenses/by-nc/4.0/ (c) (i) \&) Open Access

\begin{abstract}
The objective of this study was to describe the therapeutic aspects and to evaluate the surgery results of sigmoid Volvulus in the Kati (MALIA) General Surgery Department. Patients and Methods: This was a descriptive study conducted in our General Surgery Department. It took place in two phases for six years: A retrospective phase from January 1st, 2010 to December 31st, 2015 and a prospective phase from January 1st, 2016 to December 31st, 2017. This study has been approved by the Ethics Committee. It's concerned all the patients operated in the department for colon Volvulus. Results: We collected 70 patients' files. The Sigmoid Volvulus represented 7.8\% of emergency surgery activities and $37.2 \%$ of intestinal obstruction. The male sex predominated with $98.57 \%$ against $1.43 \%$ of the female sex. The average age was 42.11 years old with limits of 18 to 70 . The average deadline evolution was 2.53 days with limits of 1 to 3 . The sigmoidectomy with immediate anastomosis was performed in $66 \%$ of patients, colectomy with 2-times anastomosis: according to Hartman $20 \%$ and Bouilly Volkman $11 \%$, detorsion with colopexy $3 \%$. The early morbidity rate was $5.71 \%$. The average duration of hospitalization was 10.8 days with limits of 5 to 40 days. Two deaths were recorded. Conclusion: Sigmoid Volvulus is frequent in young adult sex male in Africa. We did not find any significant difference between the surgical technique and the advent of complications. The Colectomy with immediate anastomosis seems to be ideal to us that anytime the conditions are appropriate.
\end{abstract}




\section{Keywords}

Volvulus, Sigmoid, Colectomy, Surgery

\section{Introduction}

The Volvulus of the sigmoid colon is the torsion of the sigmoid loop on its mesocolic axis, realizing a low intestinal occlusion, by strangulation [1]. The main risk factor is dolichocolon. It's a surgical emergency that requires an early management at the risk of developing complications leading to necrosis and generalized acute peritonitis. In Africa, colon Volvulus is a very frequent pathology in the young adults [2] [3] [4] [5] [6]. On the other hand, in the developed countries like Europe, USA, it is the third cause of colon occlusion after cancer and diverticulosis in the elderly [7] [8]. The diagnosis remains easy, but the treatment is controversial. If in the developed countries, endoscopic colo-exsufflation followed by surgery is the consensual therapeutic approach [7] [9], in the developing countries, the surgical approach is the most widely practiced for several reasons: patients going to see the doctor at the stage of complications, financial problems, lack of technical platform for endoscopy in hospitals. In Africa, overall mortality can reach $32.1 \%$ on average in case of necrosis [6] [10] [11] and $2.17 \%$ in the absence of necrosis [4]. The absence of a study on this pathology at the Kati Hospital motivated us to initiate this work, the purpose of which was to describe the therapeutic aspects and to evaluate the surgery results of the sigmoid Volvulus colon.

\section{Patients and Methods}

We conducted a descriptive transversal study in the General Surgery Department that took place in two phases for six years: A retrospective phase from January 1st, 2010 to December 31st, 2015 and a prospective phase from January 1st. 2016 to December 31, 2017. The sample size was determined for extensive recruitment of patients with sigmoid colon Volvulus during 8 years (the period of the study). The patients operated out-of-service were not included. The variables studied were demographic (age, sex, position, address) clinical, pain, vomiting, stopping of materials and gases, abdominal ballooning, deshydratation signs and index of Karnofsky) para-clinical (blood test and X-rays), treatment and surgery results. The Patients were followed for at least 24 months seeing 84 months. Ethics: The participation in this study was voluntary. In addition, an informed consent of the patient was obtained. The information given by the patient was confidential and could only be used for research purposes. Our data were entered and analyzed from the Epi-info version 7 software. Word processing and graphics were done using Word 2016 and Excel 2016 software. Fischer Exacte was the statistical test used, considered as significant from $\mathrm{p}<$ 0.05 . 


\section{Results}

Epidemiological aspects: During 8 years we recorded 70 patients for sigmoid Volvulus out of a total of 188 cases of intestinal obstruction. During the same period, 892 patients were operated on this disease urgently. Thus, sigmoid Volvulus represented $37.2 \%$ of intestinal occlusions and $7.8 \%$ of emergency surgical activities. The average age was 42.11 years old with limits of 18 to 70 years old. The male sex predominated with $98.57 \%(69 / 70)$ against $1.43 \%(1 / 70)$ of the female sex. The average time to evolution was 2.5 days with limits ranging from 1 to 3 days.

Clinical Signs: Stopping of materials and gases, asymmetric meteorism, food vomiting associated with torsional-type abdominal pain were reported in $98 \%$ $100 \%$ of patients. Von Wahl's triad was observed in $97 \%$ of patients. Complementarytests: The radiography of the abdomen without preparation (ASP) made it possible to pose the diagnosis of occlusion by sigmoid volvulus colon in $97.1 \%$ of the patients (hydroaeric levels in double jambs). We found mixed hydroaeric levels in 2 patients and an image of double Volvulus (transverse colon and colon sigmoid in 1 patient) (Figure 1). None of the patients underwent abdominal computed tomography.

Surgical treatment:

Surgical Technique: All patients underwent a medial laparotomy straddling the umbilicus. We observed 47 cases of sigmoid volvulus without necrosis, 20 cases of necrosis, 2 cases of sigmoid volvulus with ileo-sigmoid node, 1 case of double volvulus sigmoid and transverse colon (Table 1). The surgical techniques (Figure 2) were colectomy with immediate anastomosis in 66\%, colectomy with 2-times anastomosis: according to Hartman 20\% and Bouilly Volkman 11\%,

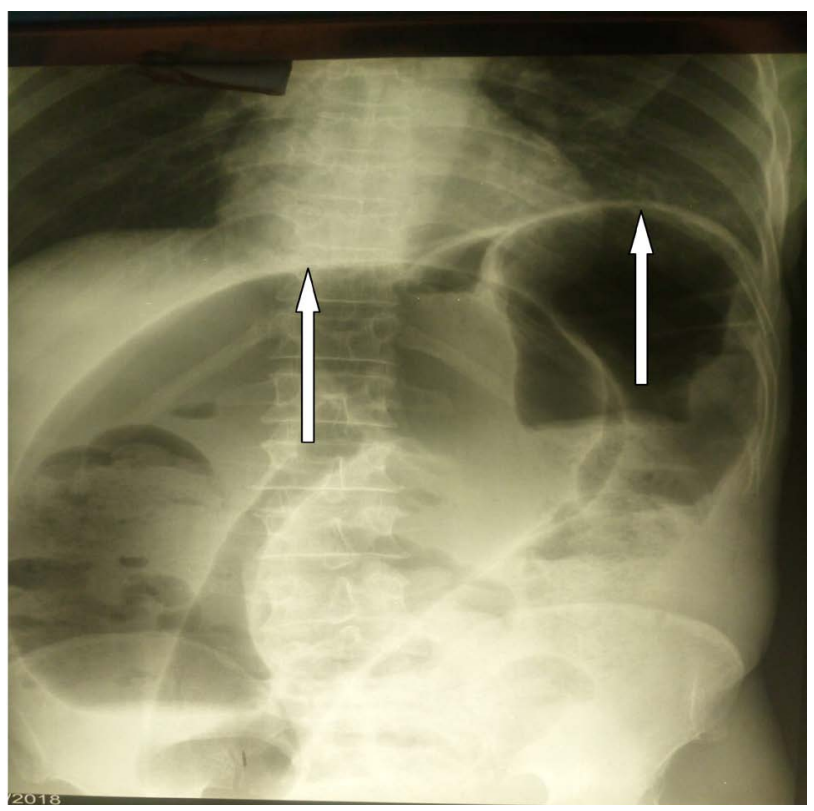

Figure 1. Image of double Volvulus (sigmoid and transverse colon). 


\section{Surgical TECHNIQUE}

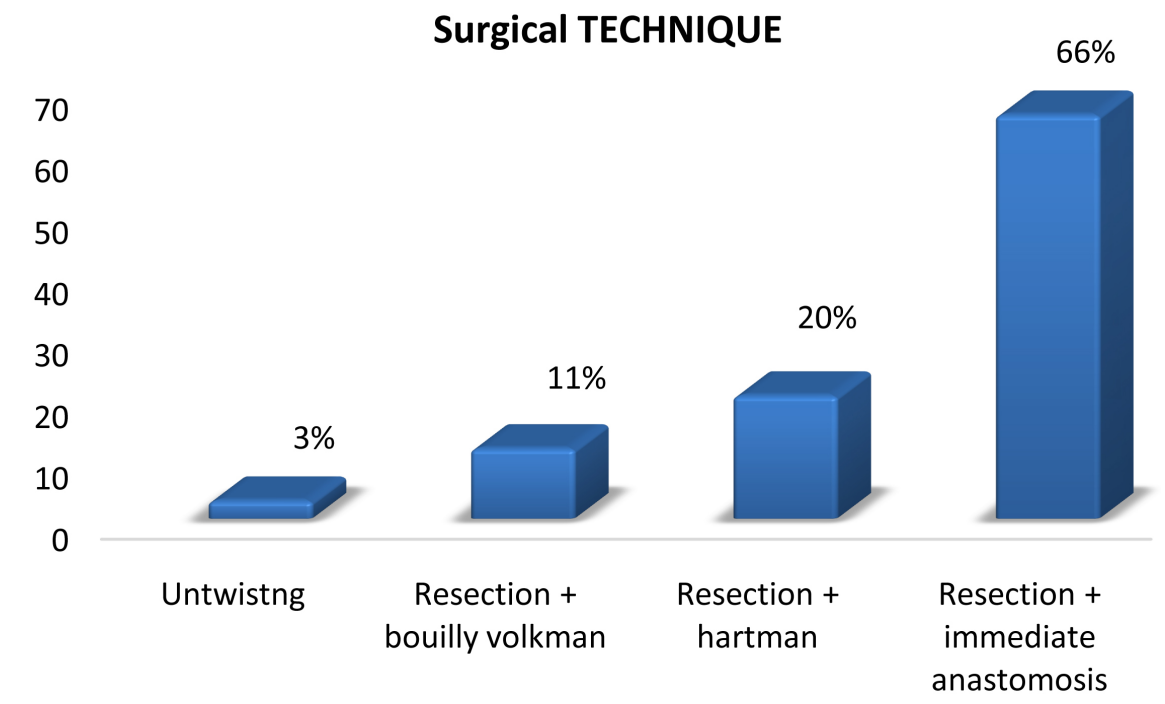

Figure 2. Distribution according to the operative techniques.

Table 1. Distribution of patients according to the peroperative diagnosis.

\begin{tabular}{ccc}
\hline Per operative & Effective & Percentage \\
\hline Sigmoid Volvulus without necrosis & 47 & 67.1 \\
Sigmoid Volvulus with necrosis & 20 & 28.6 \\
Sigmoid and hail Volvulus & 02 & 02.9 \\
Sigmoid Volvulus and Transverse Colon & 01 & 01.4 \\
Total & $\mathbf{7 0}$ & $\mathbf{1 0 0 . 0}$ \\
\hline
\end{tabular}

detorsion with colopexy $3 \%$. Of the 20 cases of necrosis, 2 patients underwent colectomy with immediate anastomosis and 18 patients underwent colectomy in 2 times.

Post-surgery results: The early post-surgery results before 1 month were simple in $91.4 \%$ of cases (Table 2). Three months later, we observed $78.6 \%$ (55/70) simple results cases, 5.7\% (4/70) post surgery incisional hernia cases and 11 patients $(15.1 \%)$ were lost from view. The average hospital stay was 10.8 days with limits of 5 and 40 days. We found a statistically significant correlation between duration of hospitalization and post surgery complications ( $p<0.044)$. On the other hand, there was no statistically significant correlation between the surgery techniques and the occurrence of complications $(\mathrm{p}<0.99)$. We deplored 2 death cases $2.9 \%(2 / 70)$.

\section{Discussion}

This study allowed to describeour therapeutic approach in the management of sigmoid colon Volvulus at Kati hospital in Mali.

We observed a frequency of 37.2\% (10 cases/year) of the sigmoid Volvulus of the intestinal occlusions. It is a frequent pathology in Africa and Asia [3] [4] [12] [13] [14] [15]. All of our patients (100\%) underwent laparotomy. This therapeutic approach is widely observed in African series in the south of the Sahara [3] 
[4] [5] [16] where patients go to see the doctor late (consultation period longer than 2 days). In addition, medical endoscopy units do not exist established in our hospitals. However in the American, Western and North African series, endoscopic devolvulation was the first step observed [9] [10] [17]. We performed colectomy with immediate anastomosis (ideal colectomy) in $66 \%$ of patients This technic was realized whenever the volvated loop was viable and the patient hemodynamically stable. This therapeutic approach is widely observed in African and Asian series [4] [12] [18] [19] [20]. Elective colectomy by Hartman and Bouilly Volkman was performed in $20 \%$ and $11 \%$ of patients respectively. Two patients 3\% underwent detorsion with colopexy. The bad perception of the colostomy by our populations, the lack of financial means, the problems of stoma management (lack of pockets and their high costs, psychic disorders, post surgery complications) have made that we had largely preferred colectomy with anastomosis immediate (ideal colectomy). The morbidity rate in our series was $5.71 \%$. We did not statistically significant correlation between the surgical technique and the advent of post surgery complications $(\mathrm{p}<0.99)$ (Table 3$)$. It was the same in the study of Togo A et al. [4] who reported that: "ideal colectomy does not present any additional risk". The mortality in our series was $2.85 \%$ (Table 4). These different mortality figures are not comparable because the complications of sigmoid volvulus differ from one study to another and the samples are not large.

Table 2. Distribution of patients according to the postoperative source.

\begin{tabular}{ccc}
\hline Immédiate follow-up (1 month) & Frequency & Percentage \\
\hline Simple & 64 & 91.4 \\
With suppuration parietal & 02 & 02.9 \\
Digestive fistula & 01 & 01.4 \\
Evisceration & 01 & 01.4 \\
Deaths & 02 & 02.9 \\
Total & 70 & 100 \\
\hline
\end{tabular}

Table 3. Relationship between surgery technique and post surgery complications.

\begin{tabular}{cccccc}
\hline \multicolumn{5}{c}{ Post surgery complications } \\
\hline $\begin{array}{c}\text { Surgery } \\
\text { technique }\end{array}$ & evisceration & $\begin{array}{c}\text { digestive } \\
\text { Fistula }\end{array}$ & simple & $\begin{array}{c}\text { Parietal } \\
\text { Suppurationn }\end{array}$ & Total \\
\hline $\begin{array}{c}\text { Idéale } \\
\text { colectomy }\end{array}$ & 00 & 01 & 64 & 00 & 65 \\
$\begin{array}{c}\text { Hartman } \\
\text { Colostomy }\end{array}$ & 01 & 00 & 00 & 00 & 01 \\
$\begin{array}{c}\text { B. Volkman } \\
\text { Colostomy } \\
\text { Detorsion }\end{array}$ & 00 & 00 & 00 & 02 & 02 \\
Total & 00 & 00 & 02 & 00 & 02 \\
\hline $\mathrm{p}=0.99$. & 01 & 01 & 66 & 02 & 70 \\
\hline
\end{tabular}


Table 4. Overall mortality by authors.

\begin{tabular}{ccc}
\hline Authors & Effective & Mortality \\
\hline Atamanalp S. S., 2011 [15] & 447 & $72(16.1 \%)$ \\
Naseer, Pakistan, 2010 [13] & 30 & $1(3.33 \%)$ \\
Ghariani, Tunis, 2010 [9] & 40 & $4(10 \%)$ \\
Nuhu, Nigeria, 2010 [2] & 48 & $5(10.4 \%)$ \\
Traoré D, Mali, 2013 [3] & 96 & $7(7.3 \%)$ \\
Togo A, Mali, 2014 [4] & 138 & $2(0.01 \%)$ \\
Sani R, Niger, 2003 [6] & 68 & $13(19.12 \%)$ \\
Our study & 70 & $2(2.86 \%)$ \\
\hline
\end{tabular}

\section{The Limits of the Study}

The monocentric nature, the size of the sample (70 patients) has a negative impact on the value of our study. It will be better in a multicentric setting where the sample size would have been very high. The lack of preoperative CT scan, coupled with the lack of endoscopic unit for coloexulfation, somewhat skews comparisons with literature data.

\section{Conclusion}

Sigmoid Volvulus is a surgical emergency. Endoscopic devolvulation is the ideal but anastomosis resection in one time at our context is an ideal alternative.

\section{Conflicts of Interest}

The authors declare no conflicts of interest regarding the publication of this paper.

\section{References}

[1] Millat, B., Guillon, F. and Avila, J.M. (1993) Acute Intestinal Occlusions of the Adult. EMC Gastroenterology, 9-044-A-10.

[2] Nuhu, A. and Jah, A. (2010) Acute Sigmoid Volvulus in a West African Population. Department of Surgery. Annals of African Medicine, 9, 86-90. https://doi.org/10.4103/1596-3519.64747

[3] Traore, D., Coulibaly, B., Togola, B., Bengaly, B, Mariko, Y., Traore, Y., Diallo, S., et al. (2013) Volvulus of Colon Sigmoid: Surgical Treatment and Prognosis in the Departments of General Surgery of the Point G CHU. Mali Medical, 3, 13-16.

[4] Togo, A., Kanté, L., Diakité, I., Dembélé, B.T., Traoré, A., Samaké, B., Coulibaly, Y., et al. (2014) Sigmoid Volvulus without Gangrenous: Primary Anastomosis Reversus Anastomosis in 2 Times? Journal Africain d'Hépato-Gastroentérologie, 61-65.

[5] Sule, A.Z. and Ajibad, A. (2011) Adult Large Bowel Obstruction: A Review of Clinical Experience. Annals of African Medicine, 10, 45-50. https://doi.org/10.4103/1596-3519.76586

[6] Sani, R., Ganda, O.R., Harouna, Y.D., et al. (2003) Sigmoid Volvulus Treatment in National Hospital of Niamey: For 68 Cases. Journal Africain de Chirurgie Digestive, 2, 277-280. 
[7] Bruzzi, M., Veron, T. and Douart, R. (2016) Management of the Volvulus of the Sigmoid Colon. Newpaper, 10, 1005-1013.

[8] Kunin, N., Letoquart, J.P., Gamina, A. and Mambrini, A. (1992) Volvulus of the Colon about 37 Cases. Journal de Chirurgie Paris, 129, 531-536.

[9] Ghariani, B., Houissa, H. and Sebai, F. (2010) Management of Sigmoid Volvulus. Hopital LaRabta Chirurgie B Tunis, 88, 163-167.

[10] Safioleas, M., Chatziconstantinou, C., Felecouras, E., Stamatakos, M., Papaconstatinou, I., Smirnis, A., et al. (2007) Clinical Considerations and Therapeutic Strategy for Sigmoid Volvulus in the Elderly: A Study of 33 Cases. World Journal of Gastroenterology, 13, 921-924. https://doi.org/10.3748/wjg.v13.i6.921

[11] Madiba, T.E. and Thomson, S.R. (2000) The Management of Sigmoid Volvulus. Journal of the Royal College of Surgeons of Edinburgh, 45, 74-80.

[12] Cisse, M., Djibo, D., Keita, S., Traore, B. and Diallo, G. (2012) Volvulus of the Sigmoid Colon in the General Surgery Department of the Somin Dolo Hospital in Mopti: 100 Cases. Medical Thesis, Bamako, 86.

[13] Naseer, A., Ahamad, S., Naeem, M. and Safirullah (2010) One Stage Emergency Resection and Primary Anastomosis for Sigmoid Volvulus. Journal of the College of Physicians and Surgeons_-Pakistan, 20, 307-309.

[14] Zhong, Y.S., et al. (2011) Emergency Colonoscopy in the Diagnosis and Treatment of Acute Colorectal Obstruction. Zhonghua Yi Xue Za Zhi, 91, 524-527.

[15] Atamanalp, S.S. and Ozturk, G. (2011) Sigmoid Volvulus in the Elderly: Outcomes of a 43-Year, 453-Patient Experience. Surgery Today, 41, 514-519. https://doi.org/10.1007/s00595-010-4317-x

[16] Toure, C.T., Dieng, M., Mbaye, M., Sanou, A., Ngom, G., Ndiaye, A., et al. (2003) Result of Emergency Colectomy in the Treatment of Sigmoid Colon Volvulus at Dakar CHUv. Annales de Chirurgie, 128, 98-101.

[17] Codinacazador, A., Farrescol, R., Olivelpujol, F., Pujadas de palol, M., Martin Grillo, A., Gomez romeu, N., et al. (2011) Colonic Volvulus and Recurrence of Volvulus: What Should We Do? Cirugia Spain, 89, 237-242.

[18] Beggui, N. (2010) The Sigmoid Volvulus about 27 Cases. Thesis Medicine Fez Morocco, 082.

[19] Khanna, A.K., Kumar, P. and Khann, R. (1999) Sigmoid Volvulus. Colon Rectm, 8, 1081-1084. https://doi.org/10.1007/BF02236708

[20] Utal, D. and Ghosh, S. (2003) Single Stage Primary Anastomosis without Colonic lavage for Left Colonic Obstruction Due to Acute Sigmoid Volvulus: A Prospective Study of one Hundred and Ninety-Seven Cases. ANZ Journal of Surgery, 73, 390-392. https://doi.org/10.1046/j.1445-2197.2003.t01-2-02654.x 